\title{
Curing Kinetics and Mechanism Research of E44/T31 Insulation Paint
}

\author{
Haoqing XU ${ }^{1,2}{ }^{*}$, Yuan FANG ${ }^{3}$, Aizhao ZHOU ${ }^{1}$, Pengming JIANG ${ }^{1}$, Shi SHU ${ }^{2}$, \\ Liang CHEN ${ }^{2}$, Shengwei WANG ${ }^{4}, \mathrm{Li}_{\mathrm{WEI}}{ }^{5}$
}

\author{
${ }^{1}$ School of Architecture and Civil Engineering, Jiangsu University of Science and Technology, No.2 Mengxi Road, \\ Zhenjiang 212003, China \\ ${ }^{2}$ Key Laboratory of Ministry of Education for Geomechanics and Embankment Engineering, Hohai University, No.1 \\ Xikang Road, Nanjing 210098, China \\ ${ }^{3}$ Physical Education College of Jiangsu University of Science and Technology, No.2 Mengxi Road, Zhenjiang, China \\ ${ }^{4}$ Institute of Geotechnical Engineering of Yangzhou University, No.88 Daxue South Road, Yangzhou 225127, China \\ ${ }^{5}$ Department of Materials Science and Engineering of Shenyang Ligong University, No.6 Nanping Middle Road, Shenyang \\ 110159, China
}

crossref http://dx.doi.org/10.5755/j01.ms.25.4.22095

Received 19 November 2018; accepted 31 March 2019

\begin{abstract}
Epoxy resin insulation paint was prepared with epoxy resin (E44) as binder and with proper inorganic fillers and curing agent (T31) as additives. The isothermal curing reaction process of paint was studied by the differential scanning calorimetry method (DSC), and the curves of curing reaction rate versus time of paint were obtained. The curing reaction kinetics was investigated by using the phenomenological method, and the corresponding parameters of the $\mathrm{n}$-order model, autocatalytic model and Kamal model were determined by fitting the experimental data, respectively. According to the values of $R^{2}$ and the sum of square due to error (SSE), a suitable curing reaction kinetic model was determined. The curing reaction mechanism of paint was ascertained by the dynamic temperature DSC method and IR spectroscopy (FTIR) method. The results show that the Kamal model can be used to describe the curing kinetics of epoxy resin paint, and the total reaction orders increase from 1.30 to 2.14. The two rate constants increase with the increase of the curing temperature. The activation energy is $90.5832 \mathrm{~kJ} / \mathrm{mol}$ and $68.3733 \mathrm{~kJ} / \mathrm{mol}$ respectively, and the pre-exponential factors are $6.521 \times 10^{15} \mathrm{~s}^{-1}$ and $6.3807 \times 10^{9} \mathrm{~s}^{-1}$. The curing reaction of paint consists of two steps: the first step is the addition reaction of epoxy group and primary amine or secondary amine; the second step is the etherification reaction of epoxy group and phenolic hydroxyl or alcoholic hydroxyl.

Keywords: epoxy resin (E44), insulating coatings, DSC, curing kinetics, reaction mechanism.
\end{abstract}

\section{INTRODUCTION}

Epoxy resin insulation paint, which is prepared with epoxy resin (E44) as binders, exhibits good heat resistance, fast curing rate, strong bonding strength and good water resistance $[1,2]$, etc. The addition of inorganic fillers not only gives the paint a better heat insulation property [3], but also reduces the curing shrinkage rate, and enhances its mechanical properties [4]. Curing agent (T31), which can cure the paint at a low temperature or room temperature, may improve the performance of curing products [5]. Therefore, the epoxy resin insulating paint that is specially prepared can be applied in many special occasions, such as the thermal protection of internal and external surfaces of ammunition, coating agent of artillery ammunition column, heat protection of engine combustor liner and facilities on the ground, as well as the heat insulation protection of petroleum and chemical heat pipe, engine cylinder of transportation and exhaust pipe, etc.

The curing reaction kinetics of the epoxy resin system is an important foundation of the epoxy resin insulation paint; the research in the related fields can provide theoretical guidance and basis for the coating-forming. Isothermal DSC is the most commonly used test method to

\footnotetext{
* Corresponding author. Tel.: +86 15751778209;

fax: +86 051184402322. E-mail address: hankinxu@163.com (H. Xu)
}

study curing reaction kinetics [6], and the phenomenological method is a widely used modeling method to examine the curing reaction kinetics of epoxy resin system by using empirical equations as the basis equations of curing reaction kinetics and using mathematical modeling to obtain each parameter in the model equation $[7,8]$.

In this paper, under the condition of the determined paint composition, the isothermal curing reaction process of paint was studied by the isothermal DSC method, and the curing reaction kinetics was studied by applying the norder model, autocatalytic model [7] and Kamal model [9], which are all applicable to the epoxy resin of the phenomenological method. Then, the most suitable kinetic model and parameters of paint were determined and the dynamic equation was obtained. The curing reaction mechanism of paint was ascertained by the dynamic temperature DSC method and IR spectrogram (FTIR) method. All above provide the theoretical foundation for the preparation and technology of epoxy resin insulating paint.

\section{EXPERIMENTAL DETAILS}

\subsection{Paint material}

Epoxy resin (E44) and Curing agent (T31) are from Shenyang zhengtai anticorrosive material co. LTD. Mica, 
aluminium oxide and magnesium oxide come from Sinopharm group chemical reagent co. LTD.

\subsection{Preparation of paint}

Three kinds of inorganic matters A, B and C were put into the jar proportionally as heat insulation fillers, and were mixed and stirred evenly at the speed of $1200 \mathrm{r} / \mathrm{min}$ to make them into powders. Then the powders and a small amount of additives were added into the epoxy resin (E44), scattered evenly at a high speed to make them into slurry. Finally, the curing agent (T31) was added into the slurry, and the epoxy resin paint was produced after stirring at a low speed and room temperature $\left(25 \pm 1^{\circ} \mathrm{C}\right)$.

\subsection{Experimental method}

\subsubsection{Differential scanning calorimetry analysis (DSC)}

The prepared fresh paint was put into a corundum DSC pan as a sample (about $20 \sim 50 \mathrm{mg}$ ), and was scanned by the high pressure differential scanning calorimeter (DSC) with $204 \mathrm{HP}$ type (German NETZSCH) in $\mathrm{Ar}$ atmosphere $(20 \mathrm{ml} / \mathrm{min})$ at the pressure of $20 \mathrm{bar}$. The sample was then monitored at the isothermal temperature after heating up to the specified temperature. The isothermal curing reaction heat of the sample was denoted as $\Delta H_{i}$. The sample was rapidly cooled to $20^{\circ} \mathrm{C}$, and then scanned at the heating rate of $10^{\circ} \mathrm{C} / \mathrm{min}$ to $250{ }^{\circ} \mathrm{C}$. The rest of curing reaction heat of the sample was denoted as $\Delta H_{r}$, and the total curing reaction heat was calculated as $\Delta H_{o}=\Delta H_{i}+\Delta H_{r}$.

\subsubsection{IR spectroscopy analysis (FTIR)}

After the paint was fully cured at isothermal $30^{\circ} \mathrm{C}$ (to achieve the maximum curing degree of the condition), ground it into powders. The sample was prepared by using the $\mathrm{KBr}$ tabletting method, and then measured by the Fourier transform infrared spectroscopy with a 380 FTIR spectrometer (Thermo Fisher, USA) in the range of $4000 \sim 400 \mathrm{~cm}^{-1}$.

\section{RESULTS AND DISCUSSION}

\subsection{DSC analysis of paint with different filler contents}

Fig. 1 shows the DSC curves of paint with different filler contents in the curing process $\left(50^{\circ} \mathrm{C}\right)$, among which, the inorganic filler content was prepared according to the percentage of weight of fillers in epoxy resins. The curing agent (T31) content is $20 \%$ according to the percentage of weight of curing agent in epoxy resins.

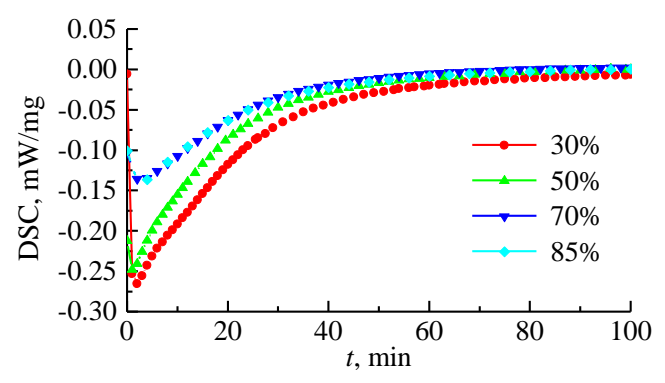

Fig. 1. DSC curves of paint in the curing process $\left(50^{\circ} \mathrm{C}\right)$
It can be seen from Fig. 1 that all heat-release rates reach the peak value quickly, and then begin to decrease and eventually approach to zero in the curing reaction of paint with different filler contents. When the inorganic filler content is eaual to $30 \%$, the curing heat-release rates of the unit mass of paint are the fastest; when the inorganic filler content is equal to $70 \%$ or $85 \%$, the curing heatrelease rates are getting lower and there is almost no difference between different filler contents. During the curing reaction process, the more content of inorganic filler, the more moderate the heat-release reaction is; in other words, the curing heat-release rate of the unit mass of paint decreases with the increase of the inorganic filler content in paint. This is because the more content of inorganic filler, the less content of epoxy resin is, and therefore, the heat-release rate of the unit mass of paint decreases.

\subsection{Isothermal curing kinetics model of epoxy resin paint}

It is a common analysis method to use DSC data to derive the curing kinetic parameters. In the curing reaction process, the most commonly used universal dynamic equation at the isothermal temperature [9] is as follows:

$d \alpha / d t=K(T) \cdot f(a)$,

where the reaction rate constant $K(T)$ is described by an Arrhenius equation: $K(T)=\mathrm{A} \cdot \exp \left[-E_{a} / R T\right] ; f(a)$ is a model function that depends on reaction mechanism; $\alpha$ is the curing degree; $A$ and $E_{a}$ refer to the former factor and the reaction activation energy respectively. In the curing reaction, the curing reaction heat measured by DSC is directly proportional to the open-ring quantities of the epoxy group; in other words, the reaction heat is directly proportional to the curing degree $\alpha$. Thus, the cure degree can be represented by the following formula:

$\alpha=\Delta H_{t} / \Delta H_{o}$,

where $\Delta H_{t}$ is the heat released up to time $t$ and $\Delta H_{o}$ is the total reaction heat in the whole curing process. At the fixed time and temperature, $d H / d t$ is the vertical of curve, also known as the heat flow rate, which is proportional to $d \alpha / d t[10]$ :

$$
d \alpha / d t=(d H / d t) / \Delta H_{o} .
$$

Assuming that the curing process conforms to one dynamic model by using the model fitting method, then the kinetic parameters can be obtained [11]. Common curing reaction models and the corresponding kinetic parameters of the epoxy resin system are shown in Table 1.

Table 1. Curing reaction model equation and kinetic parameters of conventional thermal-setting resin

\begin{tabular}{|l|c|c|c|}
\hline $\begin{array}{l}\text { Reaction } \\
\text { model }\end{array}$ & $\begin{array}{l}\text { Model } \\
\text { name }\end{array}$ & $\boldsymbol{d} \boldsymbol{\alpha} / \boldsymbol{d} \boldsymbol{t}$ & Kinetic parameter \\
\hline $\begin{array}{l}\mathrm{n} \text {-order } \\
\text { model }\end{array}$ & $\mathrm{F}(\mathrm{n})$ & $k_{0}(1-\alpha)^{n}$ & $A, E_{a}, k_{0}, n$ \\
\hline $\begin{array}{l}\text { Autocatalytic } \\
\text { model }\end{array}$ & $\mathrm{F}(\mathrm{A})$ & $k_{1} \alpha^{m}(1-\alpha)^{n}$ & $A, E_{a}, k_{1}, m, n$ \\
\hline $\begin{array}{l}\text { Kamal } \\
\text { model }\end{array}$ & $\mathrm{F}(\mathrm{k})$ & $\left(k_{2}+k_{3} \alpha^{m}\right)(1-\alpha)^{n}$ & $A, E_{a}, k_{2}, k_{3}, m, n$ \\
\hline
\end{tabular}


$\mathrm{F}(\mathrm{n})$ represents an $\mathrm{n}$-order model; $\mathrm{F}(\mathrm{A})$ represents the autocatalytic model; $\mathrm{F}(\mathrm{k})$ is a composite model, which contains the n-order reaction and autocatalytic reaction.

\subsection{Analysis of isothermal curing process of epoxy resin paint}

Fig. 2 shows the DSC curves of epoxy resin paint in the isothermal curing process. It is clear that all the heatrelease rates of paint reach the maximum in five minutes, and then begin to decrease and finally approach to zero in the isothermal curing reaction. All the curing heat-release rates are accelerated and the maximum heat release rates appear earlier with the higher temperature in five minutes. Then, all the curing heat-release rates begin to decrease after five minutes.

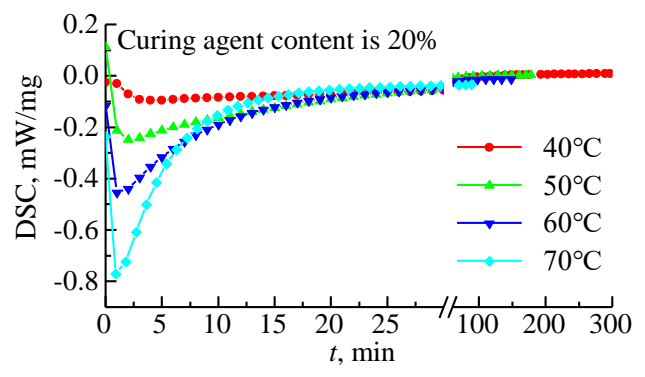

Fig. 2. DSC curves of paint in isothermal curing process

The isothermal DSC curve tangentes to the baseline, and $\Delta H_{t}$ is obtained by integrating where integral curve for time from start to $t$. Then, $\Delta H_{i}$ is obtained by integrating where integral curve for time from start to the point of tangency. The dynamic temperature DSC curve tangentes to the baseline, and $\Delta H_{r}$ was obtained by integrating where integral curve for time from start to $t$. The total curing reaction heat is calculated as $\Delta H_{o}=\Delta H_{i}+\Delta H_{r}$. The curing degree is calculated as
$\alpha=\Delta H_{t} / \Delta H_{o}$, and the total relation curves between the curing degree and time are shown in Fig. 3.

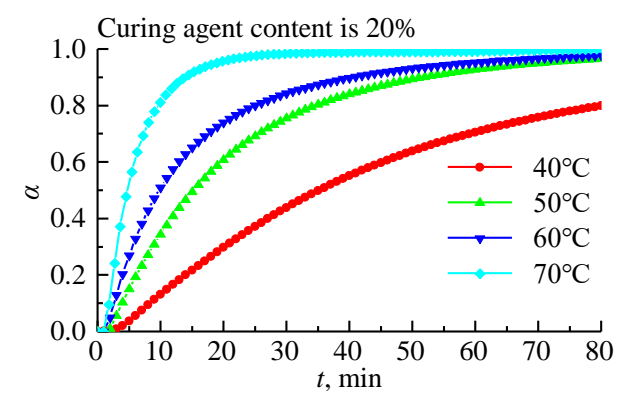

Fig. 3. Relationship of cure degree versus time of paint

Fig. 3 shows that the time to achieve the same curing degree is shortened with the increase of temperature, and the curing degree also increases within the same reaction time. The reason is that the increase of temperature accelerates the motion of epoxy resin (E44) molecules and curing agent (T31) molecules, and increases the collision probability of the epoxy groups, amino and hydroxyl in the molecules, which in turn leads to acceleration of the curing heat-release reaction. Meanwhile, it can be seen that the curing degree increases quickly at the initial stage of reaction; when the curing degree is above $80 \%$, its rise slows down. A possible explanation is that all the concentrations of epoxy groups, amino and hydroxyl, which participate in the reaction, are large at the initial stage, and the heat-release rate of reaction between the groups is fast; thus, the large amount of released heat makes the temperature rise rapidly in the system and further promotes the increase of reaction rate. The concentrations of reactive groups that participate in the reaction are gradually reduced at the later stage, which leads to decrease of the heat-release rate and reduction of the released heat.
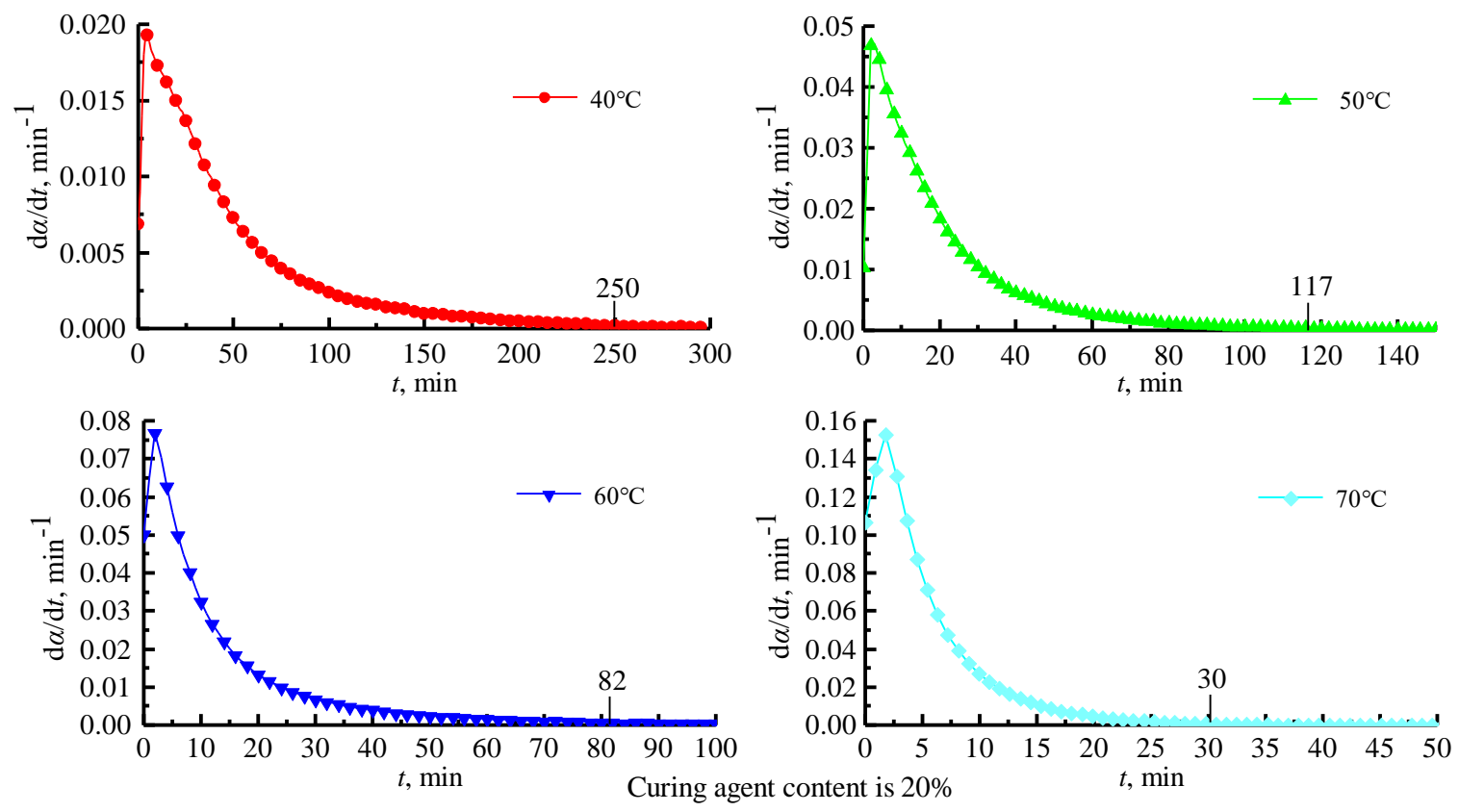

Fig. 4. Relationship of reaction rate versus time $(d \alpha / d t-t)$ of paint 
Consequently, the system constantly loses the original heat, and the temperature of the system as well as the reaction rate declines gradually. Especially after the gel point, the system begins to form a three-dimensional structure, while the relative molecular mass tends to approach to infinity ${ }^{[12]}$ and the viscosity of the system is increasing gradually, which further affects the spread of reactive groups, causing the effective collision probability of reactive groups to decline. Meanwhile, the curing reaction becomes increasingly more difficult, as its chemical control turns into diffusion control [13].

Table 2. Curing time of paint at different temperatures

\begin{tabular}{|c|c|}
\hline Temperature, ${ }^{\circ} \mathrm{C}$ & Curing time, min \\
\hline 40 & 250 \\
\hline 50 & 117 \\
\hline 60 & 82 \\
\hline 70 & 30 \\
\hline
\end{tabular}

Fig. 4 shows the relation curves between the curing reaction rate and the curing time of epoxy resin paint in the isothermal curing process. It can be seen that all the curing reaction rates increase quickly at first with the passage of time, then gradually decrease, and finally approach to zero. Put the needed time of curing reaction rate drop to zero as curing time (as shown in Table 2), it is clear that the curing reaction rate increases with the increase of curing temperature, and accordingly, the curing time is shortened at the same time.

\subsection{Determination of curing reaction kinetics equation and parameters}

A series of corresponding relationships about $d \alpha / d t$ and 1- $\alpha$ are derived from the isothermal DSC curves, and the reaction orders are concluded as follows: $k_{0}, n$ of n-order model; $k_{1}, m$ and $n$ of autocatalytic model; $k_{2}, k_{3}, m$ and $n$
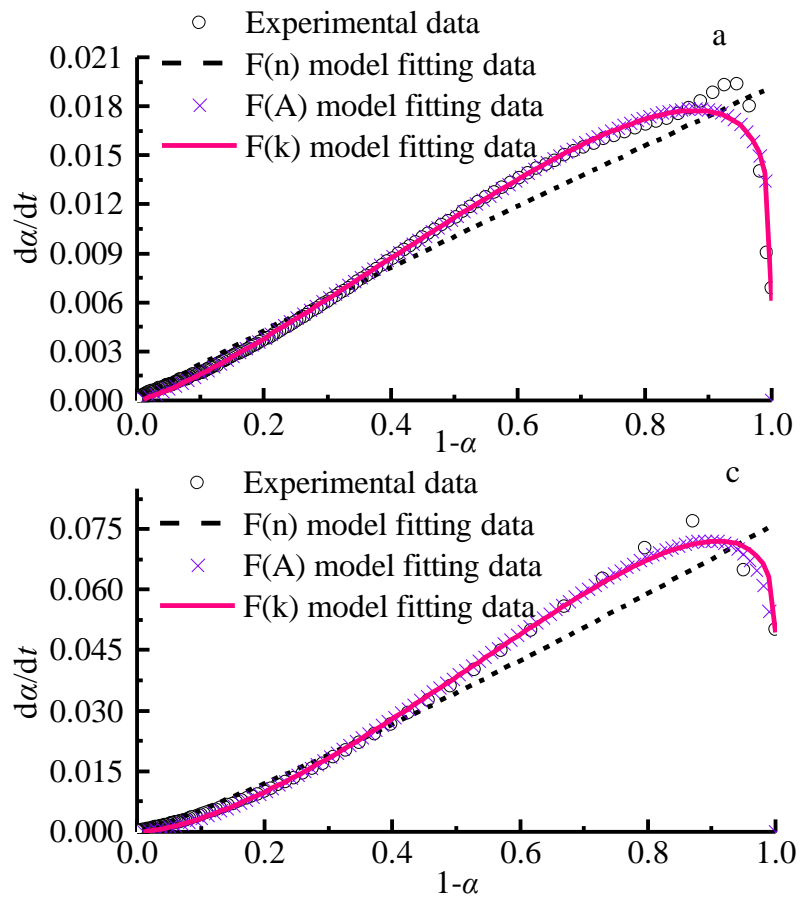

of Kamal model, by using the fitting experimental data through Origin 8.0 software. The results are shown in Fig. 5.

It can be observed from Fig. 5 that the curves of norder model can be fitted well with the experimental data at the later stage of curing reaction, but deviation exists at the initial stage of reaction. The curves of both Kamal model and autocatalytic model can be fitted well with the experimental data in the whole process of curing reaction. According to the values of $R^{2}$ and the sum of square due to error (SSE), a suitable curing reaction kinetic model is determined, and all the parameters in the three models are listed in Table 3.

As shown in Table 3, the values of $R^{2}$ in the Kamal model $\mathrm{F}(\mathrm{k})$ of fitted curves are above 0.99 , which are the closest to the ideal situation $\left(R^{2}=1\right)$, and all the sums of square due to error (SSE) are also the closest to zero. Thus, the Kamal model can well describe the isothermal curing process of epoxy resin paint. As the most suitable model, the following discussion will mainly focus on the Kamal curing model. The results also indicate that the two rate constants increase with the increase of the curing temperature. From Table 3, it can be found that the reaction rate constants $k_{2}$ and $k_{3}$ increase respectively with the increase of the curing temperature. Taking the natural logarithm of Arrhenius' equation $\left(k=\mathrm{A} \cdot \exp \left[-E_{a} / R T\right]\right.$ is $\ln k=\ln A-E_{a} /(R T)$, both $k_{2}$ and $k_{3}$ at various temperatures generate into the formula. The curves of $\ln k-1 / T$ are obtained by drawing $\ln k$ versus $1 / T$. After fitting the curves using a linear model, the results are shown in Fig. 5. A series of $\ln k$ versus $1 / T$ produces a straight line, the gradient and intercept of which can be used to determine the frequency factor $(A)$ and activation energy $\left(E_{a}\right)$.
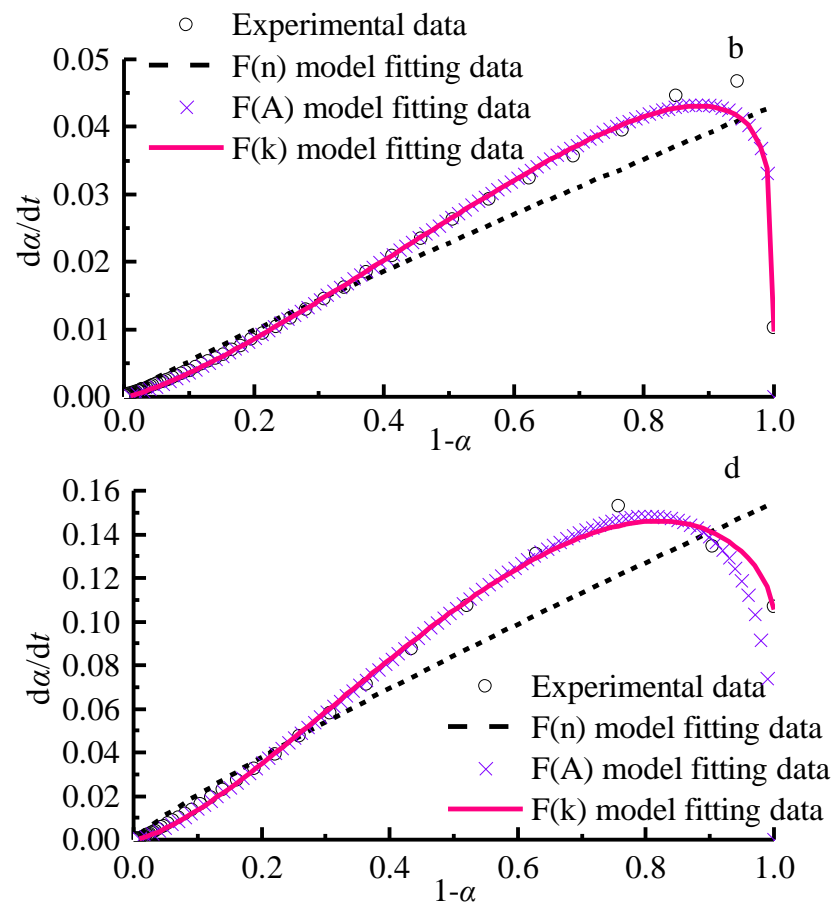

Fig. 5. Curves of $d \alpha / d t$ versus $1-\alpha$ of paint by model fitting method: $\mathrm{a}-40{ }^{\circ} \mathrm{C} ; \mathrm{b}-50{ }^{\circ} \mathrm{C} ; \mathrm{c}-60^{\circ} \mathrm{C} ; \mathrm{d}-70{ }^{\circ} \mathrm{C}$ 
Fig. 6 shows that $\ln k_{2}=29.51-10.89 \times 10^{3} / T$ and $\ln k_{3}=22.58-8.22 \times 10^{3} / T$ can be derived using the relation curves, and then the frequency factors $A_{2}=6.521 \times 10^{15} \mathrm{~s}^{-1}$ and $A_{3}=6.3807 \times 10^{9} \mathrm{~s}^{-1}$, and the activation energy $E_{\mathrm{a} 2}=90.5832 \mathrm{~kJ} / \mathrm{mol}$ and $E_{\mathrm{a} 3}=68.3733 \mathrm{~kJ} / \mathrm{mol}$ can be calculated accordingly. From Table 3, it can be seen that the reaction orders $m$ and $n$ have no obvious relationship with temperature, so taking the average of $m$ and $n$ as the reaction order separately, the values of $m$ and $n$ can be calculated: $m=0.38533$ and $n=1.41047$, and the total reaction order $m+n=1.7958$. Incorporating all the parameters into the Kamal model, its dynamic equation is obtained as follows:

$$
\frac{d \alpha}{d t}=\left[6.5 \times 10^{15} \mathrm{e}^{\frac{10895.3}{T}}+6.4 \times 10^{9} \mathrm{e}^{\left(-\frac{8223.9}{T}\right)} \alpha^{0.4}\right](1-\alpha)^{1.4}
$$

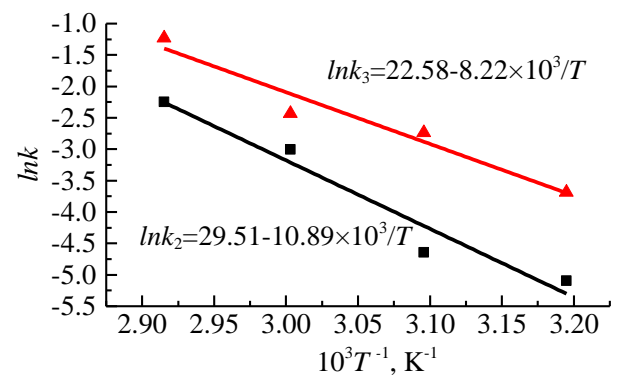

Fig. 6. Relationship of $\ln k$ versus $1 / T$ of $\mathrm{F}(\mathrm{k})$

\subsection{Discussion of curing reaction mechanism}

Epoxy resin insulating paint can be cured by curing agent (T31), and the molecular structural formula of T31 is as follows:<smiles>NPNCc1ccccc1O</smiles>

As can be seen from the formula, curing agent (T31) contains primary amine, secondary amine and phenol hydroxyl. The dynamic DSC curves of epoxy resin paint with the curing agent content of $15 \%, 20 \%$ and $30 \%$ respectively at the heating rate of $10{ }^{\circ} \mathrm{C} / \mathrm{min}$ are shown in Fig. 7.
From Fig. 7, it is clear that the paint with the curing agent content of $15 \%$ or $20 \%$ respectively has two obvious curing exothermic peaks, while the paint with the curing agent content of $30 \%$ has an obvious exothermic peak. Based on the analysis of the curing reaction process, it can be seen that when the curing agent content is equal to $15 \%$ or $20 \%$, the two exothermic peaks are caused by the addition reaction of epoxy groups with $\mathrm{N}$ atoms and the etherification reaction of the epoxy groups with hydroxyl groups.

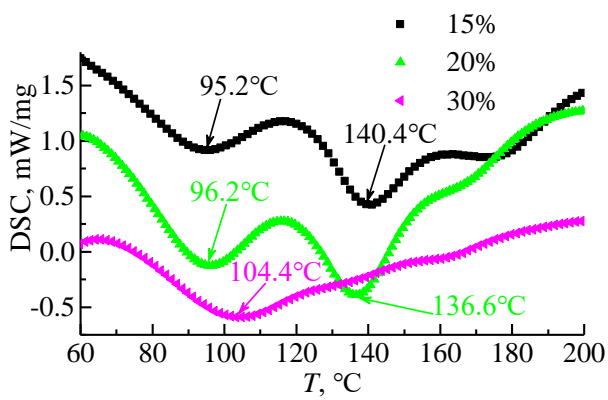

Fig. 7. Dynamic DSC of paint in curing process

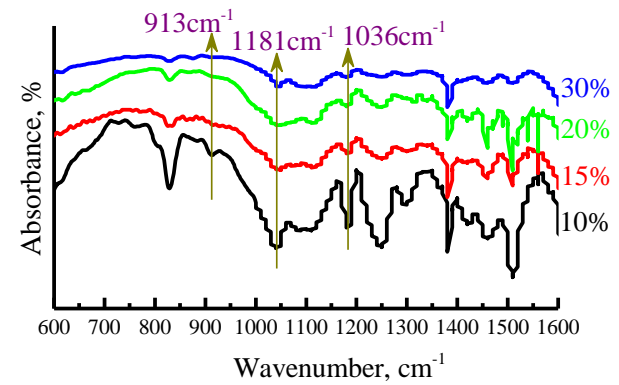

Fig. 8. FTIR spectrograms of paint

Fig. 8 shows the infrared spectra of fully cured paint at the isothermal temperature $30^{\circ} \mathrm{C}$. The absorption peak area of epoxy group peak at $913 \mathrm{~cm}^{-1}$ represents the number of epoxy group $[14,15]$, the sum of C-O-C is stretching vibration peak area of ether bond peak at $1036 \mathrm{~cm}^{-1}$ and $\mathrm{C}-\mathrm{O}-\mathrm{C}$ trans stretching vibration peak area of ether bond peak at $1181 \mathrm{~cm}^{-1}$ represents the number of ether bond ${ }^{[16]}$. We can see that when the curing agent content is equal to $10 \%$, the absorption peak area of epoxy group and the $\mathrm{C}-\mathrm{O}-\mathrm{C}$ stretching vibration peak area are both the largest.

Table 3. Kinetic parameters of paint by model fitting method

\begin{tabular}{|c|c|c|c|c|c|c|c|c|c|}
\hline Temperature, ${ }^{\circ} \mathrm{C}$ & Model & $k_{0}$ & $k_{1}$ & $k_{2}$ & $k_{3}$ & $m$ & $n$ & $S S E / \times 10^{6}$ & $R^{2}$ \\
\hline \multirow{3}{*}{40} & $\mathrm{~F}(\mathrm{n})$ & 0.0192 & - & - & - & - & 0.9371 & 1.2580 & 0.9464 \\
\cline { 2 - 10 } & $\mathrm{F}(\mathrm{A})$ & - & 0.0304 & - & - & 0.1749 & 1.2685 & 0.2839 & 0.9879 \\
\cline { 2 - 10 } & $\mathrm{F}(\mathrm{k})$ & - & - & 0.0061 & 0.0250 & 0.2487 & 1.2807 & 0.1473 & 0.9937 \\
\hline \multirow{3}{*}{50} & $\mathrm{~F}(\mathrm{n})$ & 0.0431 & - & - & - & - & 0.9143 & 10.0050 & 0.9051 \\
\cline { 2 - 10 } & $\mathrm{F}(\mathrm{A})$ & - & 0.0733 & - & - & 0.1670 & 1.3112 & 1.1288 & 0.9893 \\
\cline { 2 - 10 } & $\mathrm{F}(\mathrm{k})$ & - & - & 0.0096 & 0.0646 & 0.2103 & 1.3171 & 0.5885 & 0.9944 \\
\hline \multirow{3}{*}{60} & $\mathrm{~F}(\mathrm{n})$ & 0.0763 & - & - & - & - & 1.1487 & 9.0907 & 0.9576 \\
\cline { 2 - 10 } & $\mathrm{F}(\mathrm{A})$ & - & 0.1306 & - & - & 0.1865 & 1.5815 & 17.8353 & 0.9168 \\
\cline { 2 - 10 } & $\mathrm{F}(\mathrm{k})$ & - & - & 0.0495 & 0.0875 & 0.3890 & 1.5999 & 0.8345 & 0.9962 \\
\hline \multirow{3}{*}{70} & $\mathrm{~F}(\mathrm{n})$ & 0.1544 & - & - & - & - & 0.8738 & 56.0506 & 0.9399 \\
\cline { 2 - 10 } & $\mathrm{F}(\mathrm{A})$ & - & 0.3443 & - & - & 0.3323 & 1.3813 & 119.714 & 0.8717 \\
\cline { 2 - 10 } & $\mathrm{F}(\mathrm{k})$ & - & - & 0.1055 & 0.2920 & 0.6933 & 1.4442 & 2.14411 & 0.9977 \\
\hline
\end{tabular}


When the content of curing agent increases gradually, the absorption peak area of epoxy group is getting smaller until approaching to zero, and the stretching vibration peak area of ether bond is getting smaller too. This is because the more content of curing agent, the less the rest of epoxy group after reacted with amino, the less the etherification reaction of the epoxy group and hydroxyl, so the less ether bond which have formed, the less the rest of epoxy grourp after the reaction, until to zero.

From the analysis above, the curing mechanisms of curing agent (T31) and epoxy resin (E44) are obtained as follows:

The first step is addition reaction, where the active hydrogen of primary amine in the curing agent reacts with the epoxy group to generate secondary amine, and the active hydrogen of secondary amine (original and new generation) reacts with the epoxy group to generate tertiary amine:

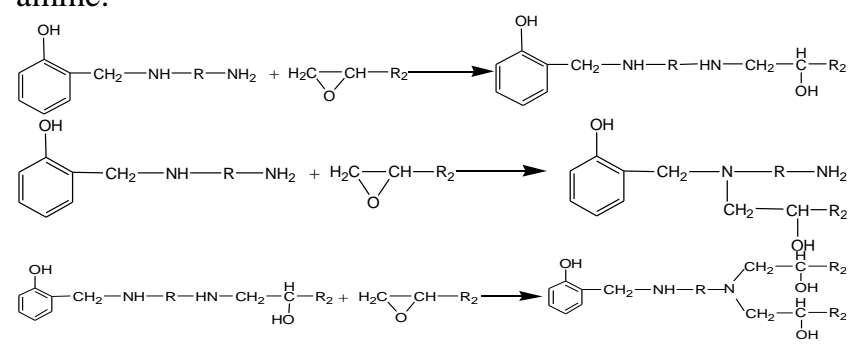

The second step is etherification reaction, where hydroxyl (the original phenolic hydroxyl and new generated alcoholic hydroxyl) reacts with the epoxy group, until the three-dimensional structure of large molecules is formed:

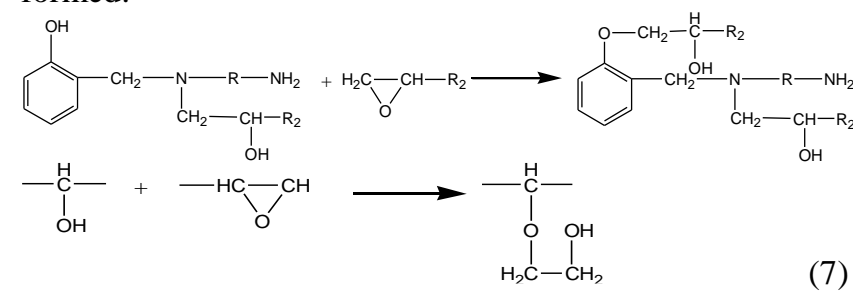

\section{CONCLUSIONS}

The curing (T31 curing agent) process of epoxy resin (E44) insulation paint was analyzed by the isothermal DSC method. The curing reaction kinetics was studied by using the phenomenological method, and the curves of curing reaction rate versus time of paint were obtained. We determine that the isothermal curing process of the epoxy resin insulating paint conforms to the Kamal model by fitting the experimental data, and the two rate constants increase with the increase of the curing temperature. Meanwhile, the activation energy $E_{\mathrm{a} 2}=90.5832 \mathrm{~kJ} / \mathrm{mol}$ and $E_{\mathrm{a} 3}=68.3733 \mathrm{~kJ} / \mathrm{mol}$, the pre-exponential factors $A_{2}=6.521 \times 10^{15} \mathrm{~s}^{-1}$ and $A_{3}=6.3807 \times 10^{9} \mathrm{~s}^{-1}$, and the total reaction order $m+n=1.7958$ all increase with the increase of temperature. Its dynamic equation is $\frac{d \alpha}{d t}=\left[6.5 \times 10^{15} \mathrm{e}^{\frac{10895.3}{T}}+6.4 \times 10^{9} \mathrm{e}^{\left(-\frac{8223.9}{T}\right)} \alpha^{0.4}\right](1-\alpha)^{1.4}$ The curing reaction mechanism of paint is ascertained by the dynamic temperature DSC method and IR spectrogram (FTIR) method. The curing reaction of paint consists of two steps: the first step is the addition reaction of epoxy group and primary amine or secondary amine; the second step is the etherification reaction of epoxy group and phenolic hydroxyl or alcoholic hydroxyl.

\section{Acknowledgments}

The authors would like to acknowledge the Natural Science Foundation of Jiangsu Province (Grant No. BK20190963, BK20170501), the Natural Science Foundation of the Jiangsu Higher Education Institutions of China (Grant No. 19KJB560003), the National Natural Science Foundation of China (Grant No. 51979128, 51579119), Key Research and Development Program (Social Development) project of Zhenjiang (Grant No. SH2018024), Key Laboratory of Ministry of Education for Geomechanics and Embankment Engineering of Hohai University (Grant No. 2018004), and China Postdoctoral Science Foundation (Grant No. 2018M640527) for supporting this study.

\section{REFERENCES}

1. Thomas, R., Durix, S., Sinturel, C., Omonov, T., Goossens, S., Groeninckx, G., Moldenaers, P., Thomas, S. Cure Kinetics, Morphology and Miscibility of Modified DGEBA-Based Epoxy Resin-Effects of a Liquid Rubber Inclusion Polymer 48 (6) 2007: pp. 1695-1710. https://doi.org/10.1016/j.polymer.2007.01.018

2. Kaynak, C., Ozturk, A., Tincer, T. Flexibility Improvement of Epoxy Resin by Liquid Rubber Modification Polymer International 51 (9) 2002: pp. $749-756$ https://doi.org/10.1002/pi.874

3. Levinson, R., Berdahl, P., Akbari, H. Solar Spectral Optical Properties of Pigments-Part I: Model for Deriving Scattering and Absorption Coefficients from Transmittance and Reflectance Measurements Solar Energy Materials and Solar Cells 89 (4) 2005: pp. 319-349. https://doi.org/10.1016/j.solmat.2004.11.012

4. Wang, D. Preparation of Fusion Bond Epoxy Powder Coatings for Interior Anticorrosive Layer of Pipeline Coatings Technology and Abstracts 33 (11) 2012: pp. $25-28$.

https://doi.org/10.3969/j.issn.1672-2418.2012.11.005

5. Zhang, X., Li, J. The Views on T-31 Epoxy Resin Curing Agent of the Phenolic Aldehyde Amine Serials China Adhesive 14 (8) 2005: pp. 52-54. https://doi.org/10.3969/j.issn.1004-2849.2005.08.014

6. Wang, Y., Wang, X., Chen, H. Studies on Curing Kinetics of Dendritic Polymer PAMAM with Epoxy Resin by Isothermal DSC Acta Polymerica Sinica 1(5) 2006: pp. $727-731$. https://doi.org/10.3321/j.issn:1000-3304.2006.05.016

7. Skordos, A.A., Partridge, I.K. Cure Kinetics Modeling of Epoxy Resins Using a Non - Parametric Numerical Procedure Polymer Engineering and Science 41 (5) 2001: pp. $793-805$ https://doi.org/10.1002/pen.10777

8. Sun, W. Curing Kinetics of DGEBA/Polyether Amine by Isothermal DSC Journal of Materials Science and Engineering 28 (6) 2010: pp. 843-847. https://doi.org/10.14136/j.cnki.issn1673-2812.2010.06.008 
9. Schawe, J.E.K. A Description of Chemical and Diffusion Control in Isothermal Kinetics of Cure Kinetics Thermochimica Acta 388 (1-2) 2002: pp. 299-312. https://doi.org/10.1016/S0040-6031(02)00041-2

10. Boey, F.Y.C., Song, X.L., Yue, C.Y., Zhao, Q. Modeling the Curing Kinetics for A Modified Bismaleimide Resin Journal of Polymer Science Part A: Polymer Chemistry 38 (5) 2000: pp. 907-913. https://doi.org/10.1002/(sici)10990518(20000301)38:5<907:aid-pola15>3.0.co;2-f

11. Zhang, J., Huang, P. Research Advances in Epoxy Resin Curing Kinetics Materials Review 23 (7A) 2009: pp. 58-61. https://doi.org/10.3321/j.issn:1005-023X.2009.13.013

12. Padma, A., Rao, R.M., Subramaniam, C., Nagendrappa, G. Cure Characterization of Triglycidyl Epoxy/Aromatic Amine Systems Journal of Applied Polymer Science 57 (4) 1995: pp. 401-411. https://doi.org/10.1002/app.1995.070570402

13. Wu, W., Liu, M., Chen, Y., Pu, W., Wu, X. Shifting of the Curing Kinetics of E-51 Epoxy Resin Acta Materiae Compositae Sinica 28 (4) 2011: pp. 1-6. https://doi.org/10.13801/j.cnki.fhclxb.2011.04.005

14. Abdelkader, A.F., White, J.R. Curing Characteristics and Internal Stresses in Epoxy Coatings: Effect of Crosslinking Agent Journal of Materials Science $40(8)$ 2005: pp. $1843-1854$.

https://doi.org/10.1007/s10853-005-1203-9

15. Gu, J., Zhang, Q., Dang, J., Zhang, J., Chen, S. Preparation and Mechanical Properties Researches of Silane Coupling Reagent Modified $\beta$-Silicon Carbide Filled Epoxy Composites Polymer Bulletin 62 (5) 2009: pp. 689-697. https://doi.org/10.1007/s00289-009-0045-z

16. Yuan, J. Some Simple Applications about Infrared Spectrum Analysis in the Reaction of Epoxy Resin with Amine Curing Agent Shanghai Coatings 41 (2) 2003: pp. 30-34.

https://doi.org/10.3969/j.issn.1009-1696.2003.02.010 